\title{
The effect of repeated stretching on the force decay and compliance of vulcanized cis-polyisoprene orthodontic elastics
}

\author{
C.C. Liu1, J.C. Wataha ${ }^{2}$, R.G. Craig ${ }^{2}$ \\ 'School of Dentistry, College of Medicine, National Taiwan University, Taipei, Taiwan ROC \\ ${ }^{2}$ Department of Biologic and Materials Science, The University of Michigan School of Dentistry, Ann Arbor, MI USA
}

\begin{abstract}
Compliance measurements, used in the past to measure the viscoelastic properties of dental impression materials, were used toassess these properties in vulcanized cis-polyisoprene orthodontic elastics, and the results were compared with traditional force decay measurements. Both methods were also used to evaluate the effect of repeated stretching on these elastics. Compliance measurements successfully characterized the viscoelastic behavior of the elastics, and the results agreed with force decaymeasurements. Repeated stretching significantly reduced the force and the compliance of the elastics. There was no statistical difference in the force or compliance measurements after the elastics were stretched more than 200 times. Stretching for 1000 cycles of $400 \%$ extension reduced elastic force by approximately $12 \%$.
\end{abstract}

\section{INTRODUCTION}

Elastics are used for orthodontic tooth movement, such as in tooth retraction, cross-bite correction, space closure, and intermaxillary traction. Traditionally, elastics have been made from either natural latex rubber or polyurethane. Both types of elastics exhibit viscoelastic rather than perfectly elastic behavior. Consequently, the force generated by an extended elastic will decrease with time (Andreasen and Bishara, 1970; Bishara and Andreasen, 1970). The amount and rate of force decay has been previously studied by several researchers (Kovatch et al., 1976; Ash and Nikolai, 1978; Varner and Buck, 1978; Brantley et al., 1979; Chang, 1987). These reports established that polyurethane elastics lost between 50 and 75 percent of their initial force during the first $24 \mathrm{~h}$ of extension and were subsequently relatively stable. When elastics are used to provide intermaxillary traction, they undergo repeated stretching as the patient talks, eats, and yawns. The effects of this repeated stretching on the viscoelastic properties of elastics have not been previously investigated.

Force gauges have traditionally been used to assess the force decay exhibited by orthodontic elastics. However, compliance measurements similar to those used to assess the viscoelasticity of impression materials should be applicable to these materials (Goldberg, 1974; Craig, 1989). Compliance measurements could be completed in less time, assess the decrease in force exhibited by these elastics, and provide information about the relative proportion of elastic, viscoelas- tic, and viscous behavior of these materials.

The purpose of these experiments was to investigate the applicability of compliance measurements to the assessment of the viscoelastic properties of vulcanized cis-polyisoprene orthodontic elastics, compare these measurements with force decay measurements, and assess the effect of repeated stretching on the force decay and compliance properties of these elastics.

\section{MATERIALS AND METHODS}

Orthodontic elastics (Ormco, Glendora, CA, USA), size 4F $(7.9 \mathrm{~mm})-170 \mathrm{~g}(1.7 \mathrm{~N})$, were used because this size of elastic is used clinically to exert force between the maxilla and mandible. These "latex" elastics were composed of vulcanized cispolyisoprene, and were rectangular in cross section with average dimensions of $1.8 \times 0.9 \mathrm{~mm}$. The average original length was $13.8 \mathrm{~mm}$. An electrically driven device was used to stretch the elastics in a straight line from a minimum of $2 \mathrm{~cm}$ to a maximum of $5 \mathrm{~cm}$. These limits were chosen because they were clinically relevant (Wheeler, 1974; Zarb et al., 1990). The frequency of the repeated stretching was one cycle per second. The elastics were stretched $0,200,500$, or 1000 times before they were tested for force decay or compliance; separate elastics were used in the force decay and compliance testing. There were five elastics in each group, and the width and thickness of each elastic was measured before and after repeated stretching with a measuring microscope accurate to $0.001 \mathrm{~mm}$.

The force exerted by the elastics before stretching was measured at $3 \mathrm{~cm}$ extension using a force gauge accurate to $10 \mathrm{~g}(0.1$ $\mathrm{N})$. The $3 \mathrm{~cm}$ extension was a convenient extension intermediate between the extremes of the repeated stretching and represented an average clinical extension, because elastics between the maxilla and mandible are constantly extended about $2 \mathrm{~cm}$ with periodic additional extensions during chewing or talking. The elastic was maintained at $3 \mathrm{~cm}$ extension between measurements, and the force was measured at $10 \mathrm{~s}, 1 \mathrm{~min}$, and 3,5,24, and $48 \mathrm{~h}$ after repeated stretching.

Compliance was measured with a device (Fig. 1) which was a modified version of an instrument used to measure the compliance of elastomeric impression materials (Goldberg, 1974). A tensile load was applied to an elastic, and the change in length of the elastic was measured via a micrometer at the top of the device. 
The micrometer was accurate to $0.02 \mathrm{~mm}$. A zeroing-load of $43 \mathrm{~g}$ (the mass of the rod and tray of the device in Fig. 1) was added to provide an accurate initial measurement of the elastic length. This load produced minimal extension of the elastic and no increase in the extension of the elastic over a 5 min period. After repeated stretching, the length of the elastic (under the zeroingload) was measured using a caliper accurate to $0.02 \mathrm{~mm}$, and the micrometer was set to zero. A test load of $200 \mathrm{~g}$ was then added to the device. The test load was chosen because it was large enough to overcome the friction in the device and small enough to avoid extension of the elastic beyond the range of the micrometer. After addition of the test load, the extension of the elastic was measured with the micrometer at $10,20,30,45$, and $60 \mathrm{~s}$, and then at $60 \mathrm{~s}$ intervals through $8 \mathrm{~min}$.

The forces measured at various times were expressed as percentages of the force before repeated stretching. Graphs of the percent force $v s$. time were used to evaluate force decay. One-way ANOVA was used to compare the force exerted by the elastics before stretching and $10 \mathrm{~s}, 5 \mathrm{~h}$, and $48 \mathrm{~h}$ after stretching. Tukey intervals were used to make pairwise comparisons $(\mathrm{p}=0.05)$.

Compliance of the elastics was calculated using the equation:

$$
J(t)_{a d j}=\varepsilon_{a}(t) / \sigma(t)
$$

where $J(t)_{a d j}$ was the compliance at time $t, \varepsilon_{\mathrm{a}}(\mathrm{t})$ was the axial strain at time $t$; and $\sigma(t)$ was the stress at time $t$, adjusted for change in cross-sectional area.

The axial strain, $\varepsilon_{\mathrm{a}}(\mathrm{t})$, was calculated by dividing the extension of the elastic at time $t$ by its length after repeated stretching. However, the original elastic width and thickness were inappropriate for calculations of $\sigma(t)$ because as an elastic was stretched, its cross-sectional area decreased significantly. To overcome this problem, it was assumed that stretching reduced the cross-sectional area of the rectangular elastic equal percentages in both the width (w) and thickness (h). The crosssectional area of the elastic was then:

$$
(\mathrm{w}-\mathrm{w} \Delta \mathrm{h} / \mathrm{h})(\mathrm{h}-\Delta \mathrm{h}) \text {, or } \mathrm{wh}-2 \mathrm{w} \Delta \mathrm{h}+\left(\mathrm{w}(\Delta \mathrm{h})^{2} / \mathrm{h}\right),
$$

where $w$ was the original width of the elastic, $h$ was the original thickness of the elastic, and $\Delta \mathrm{h}$ was the change in thickness with axial strain. Since Poisson's ratio states that:

$$
v=\varepsilon_{\mathrm{l}} / \varepsilon_{\mathrm{a}} \text { or } \Delta \mathrm{h}=v \mathrm{~h} \varepsilon_{\mathrm{a}}
$$

where $\varepsilon_{l}$ is the lateral strain $\Delta h / h$, and $\varepsilon_{a}$ is the axial strain, the combination of the equations (2) and (3) yielded:

$$
\text { Adjusted Area }=2 w h\left(1-2 v \varepsilon_{a}+v^{2} \varepsilon_{a}{ }^{2}\right)
$$

The factor of 2 in Eq. 4 accounts for both strands of the elastic (Fig. 1). Using this equation, the stress at time t was calculated as:

$$
\sigma(\mathrm{t})=\mathrm{F} / \text { Adjusted Area, where } \mathrm{F}=\text { test load. }
$$

Since it was not appropriate to employ Poisson's ratio if the material experienced plastic strain (Caddell, 1980; Gere and Timoshenko, 1984), the equation for adjusted area only applied before viscous deformation had time to occur. Therefore, the adjusted area was calculated using the axial strain at $10 \mathrm{~s}$ when little or no viscous stain had occurred, and nonuniform deformation was minimal. This assumption accounted for greater than $90 \%$ of the change in cross-sectional area because $90 \%$ of the strain occurred within $10 \mathrm{~s}$. The stress, $\sigma(\mathrm{t})$, was

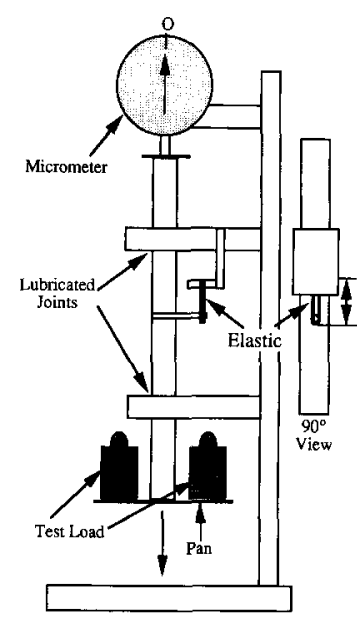

Fig. 1. Device used to measure the compliance of the elastics. A minimal zeroingload (the mass of the pan and rod) was added to establish the length after repeated stretching. The test load was added after zeroing. A micrometer was used to measure the extension of the elastic at different times.

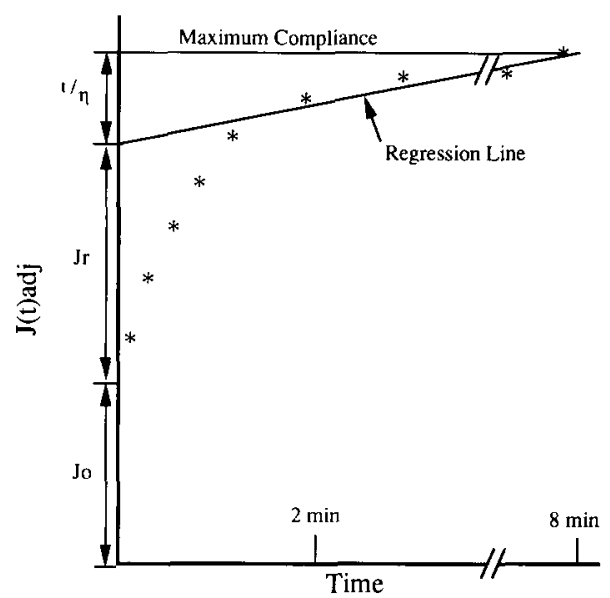

Fig. 2. The graphical method by which the total compliance (J(t)adj) of an elastic was divided into its elastic (Jo), viscoelastic (Jr), and viscous $(t / \eta)$ components. The $y$ intercept of a least squares simple linear regression line from 2 to $8 \mathrm{~min}$ was used to determine the boundary between $\mathrm{t} / \eta$ and $\mathrm{Jr}$. The data points at early times ( $<1 \mathrm{~min}$ ) were used to find the boundary between Jo and $\mathrm{Jr}$.

assumed to be constant at times after $10 \mathrm{~s}$ because the crosssectional area was changing only slightly and the applied load was constant. In this manner, the majority $(>90 \%)$ of the change in cross-sectional area was taken into account without violating the assumptions of Poisson's ratio. Poisson's ratio was taken to be 0.5 , which is typical for rubber materials (Craig, 1989).

The compliance at each time interval was calculated, and these values were plotted as a function of time, resulting in a graph similar to Fig. 2. Values for the elastic, viscoelastic, and viscous components of the compliance, represented by Jo, Jr, and $t / \eta$, respectively, were obtained graphically as shown in Fig. 2. The methods for calculating these parameters have been published previously (Goldberg, 1974). Simple linear regression was used to obtain a best fit line from 2 to $8 \mathrm{~min}$, and the y-intercept of this line was taken as the boundary between $\mathrm{Jr}$ and $t / \eta$. Jo was obtained by estimating the y-intercept of the curve. Values for Jo, Jr, and $\mathrm{t} / \eta$ were averaged within each group and were compared with one-way ANOVA and Tukey multiple comparison intervals. In addition, the values for $\mathrm{J}(\mathrm{t})$ adj over all 


\begin{tabular}{|c|c|c|c|c|c|c|c|c|}
\hline \multicolumn{9}{|c|}{$\begin{array}{c}\text { TABLE 1: PERCENTAGE OF FORCE EXERTED BY ELASTICS BEFORE AND } \\
\text { AFTER REPEATED STRETCHING }\end{array}$} \\
\hline \multirow[b]{2}{*}{$\begin{array}{l}\text { No. of } \\
\text { Cycles }\end{array}$} & \multicolumn{8}{|c|}{ Time After Repeated Stretching } \\
\hline & $\begin{array}{l}\text { Before } \\
\text { Stretching }\end{array}$ & $10 \mathrm{~s}$ & $1 \mathrm{~min}$ & $1 \mathrm{~h}$ & $3 \mathrm{~h}$ & $5 \mathrm{~h}$ & $24 \mathrm{~h}$ & $48 \mathrm{~h}$ \\
\hline \multirow[t]{2}{*}{$0^{*}$} & $100.0^{\star *}$ & $100.0^{\ddagger}$ & $92.9^{\ddagger}$ & 91.3 & 90.0 & 89.4 & 86.2 & 86.0 \\
\hline & & & $(0.3)$ & $(1.7)$ & (2.5) & (1.7) & $(1.7)$ & $(1.2)$ \\
\hline \multirow[t]{2}{*}{200} & 100.0 & 91.0 & 86.0 & 87.5 & 88.0 & 87.2 & 85.0 & 82.6 \\
\hline & & (1.1) & (2.2) & (3.1) & $(3.0)$ & (1.9) & $(2.6)$ & (2.2) \\
\hline \multirow[t]{2}{*}{500} & 100.0 & 88.7 & 84.8 & 87.2 & 89.1 & 85.2 & 82.1 & 83.2 \\
\hline & & (1.4) & $(0.8)$ & $(0.9)$ & (1.9) & (2.6) & (2.3) & (2.2) \\
\hline \multirow[t]{2}{*}{1000} & 100.0 & 88.0 & 84.0 & 86.7 & 86.4 & 85.1 & 82.2 & 81.7 \\
\hline & & $(3.0)$ & (2.8) & $(2.0)$ & $(2.2)$ & (3.2) & (2.9) & $(2.4)$ \\
\hline \multicolumn{9}{|c|}{ 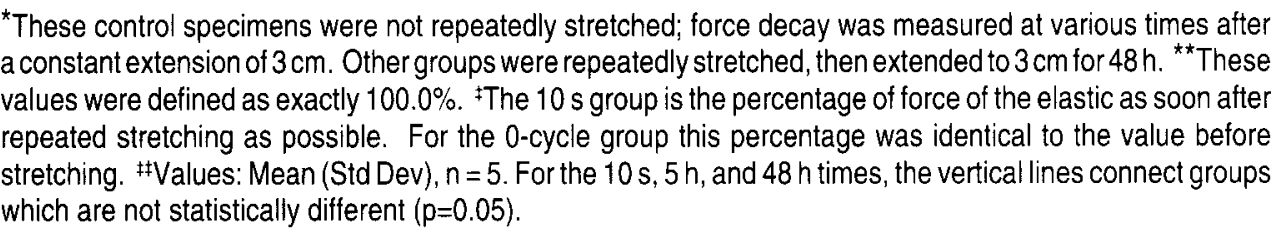 } \\
\hline
\end{tabular}

showed that the 0 cycle group was significantly different from the 200 , 500 , and 1000 cycle groups, but that there were no significant differences among the stretched groups.

Table 2 summarizes the values of Jo, Jr, and t $/ \eta$ which were generated from the compliance-time graphs. All three parameters decreased when the number of stretching cycles was increased, but the differences were not always significant. Jo and $t / \eta$ values decreased significantly ( $p=0.003$ ) between the 0 and 200 cycle groups, but there were no significant differences among the 200,500 , and 1000 cycle groups for these parameters. Jr values also decreased with repeated stretching, but only the 0 and 1000 cycle groups were significantly different. Although repeated stretching reduced the total compliance of the elastics, the relative contribu-

cycles were compared at the 5 min time with one-way ANOVA. Finally, the relative proportions of $\mathrm{J}_{0}, \mathrm{Jr}$, and $\mathrm{t} / \eta$ were compared within each group.

\section{RESULTS}

Force decay of the cycled elastics is shown in Table 1 . The average force exerted by the elastics before repeated stretching was $290 \mathrm{~g}$ $(2.8 \mathrm{~N})$. The force exerted by the control specimens which were not stretched decreased approximately $7 \%$ during the first minute of extension, but decreased only an additional $7 \%$ over the next $48 \mathrm{~h}$. Elastics which were repeatedly stretched showed an initial drop in force followed by a slight recovery, and subsequent decay paralleling that of the control elastics. For example, the elastics which were cycled 200 times exhibited a $9 \%$ drop in force immediately after repeated stretching and an additional 5\% drop during the first minute, followed by a slight recovery between 1 and $3 \mathrm{~h}$ and subsequent decline thereafter to about $83 \%$ of their original force. Although the recovery was apparent in all groups except the control group, it was not statistically significant. Increasing the number of stretching cycles caused a larger initial drop in force, although the largest difference was observed between the 0 cycle and 200 cycle groups.

The forces exerted by the control group were compared statistically with the stretched groups at $10 \mathrm{~s}, 5 \mathrm{~h}$ and $48 \mathrm{~h}$ (Table 1). Tukey intervals showed that the 0 cycle group differed significantly from the other groups $10 \mathrm{~s}$ and $48 \mathrm{~h}$ after stretching. At $5 \mathrm{~h}$, the 0 cycle group differed significantly only from the 500 cycle and 1000 cycle groups. The 200,500 , and 1000 cycle groups were statistically indistinguishable at all three times (Table 1).

Fig. 3 summarizes the compliance results. Increasing the number of stretching cycles decreased the compliance of the elastics, and the largest effect was evident between the 0 cycle and 200 cycle groups. In addition, the slope of the curves from 2 to 8 min decreased slightly as the number of cycles increased. Analysis of variance showed that compliance at 5 min among the groups of elastics was significantly altered by the repeated stretching $(\mathrm{p}=0.003)$. Tukey comparisons among the groups tions of Jo, Jr, and t/n did not change substantially (Table 2).

\section{DISCUSSION}

Since increasing the number of stretching cycles from 500 to 1000 caused little additional force decay (Table 1), additional stretching cycles beyond 1000 probably would not have a dramatic impact on the force. Considering that the elastics were subjected to 1000 cycles of stretching which extended them almost $400 \%$ per cycle, it is remarkable that the force decay did not change more. These results would indicate that materials composed of vulcanized cis-polyisoprene are well suited for clinical situations where repeated stretching would occur. However, this type of testing might reveal significant deficiencies in other types of orthodontic elastics.

The repeated stretching apparently caused structural changes in the elastics as manifested by the changes in force and compliance. These changes were apparently not cumulative, since the decay in these properties did not increase with increased repeated stretching (Table 1 and Fig. 3). With this material, these changes did not appear to be permanent, since the viscous component of the compliance was relatively small (Table 2). Although the recovery in force was not statistically significant, it occurred in all groups to some extent except the control group (Table 1). The cause of the recovery is not known, but it may have resulted from a time-dependent reorganization of polymer chains which were disrupted during the repeated stretching.

The compliance method was an efficient method of evaluating the performance of orthodontic elastics. Clinically, viscoelastic and viscous behavior are not desirable since they result in a loss of force which is generally not predictable. The compliance method quantified the elastic, viscoelastic, and viscous behavior of elastics with a relatively simple device, and detected changes in these properties after repeated stretching (Fig. 3). This method appeared sensitive enough to be of use in screening these types of materials, since it was able to easily detect the viscoelastic and viscous components of vulcanized cispolyisoprene ("latex") elastics which exhibit only minimal vis- 


\begin{tabular}{|lccc|}
\hline $\begin{array}{r}\text { TABLE 2: CONTRIBUTION OF Jo, Jr, AND t/7 TO TOTAL COMPLIANCE } \\
\left(\mathrm{MPa}^{-1} \text { ) }\right.\end{array}$ & BEFORE AND AFTER REPEATED STRETCHING \\
\hline Group & Jo & $\mathrm{Jr}$ & $\mathrm{t} / \eta$ \\
\hline 0 Cycles & $0.35(0.07)^{*}$ & $0.066(0.018)$ & $0.019(0.005)$ \\
200 Cycles & $0.25(0.07)$ & $0.046(0.014)$ & $0.011(0.003)$ \\
500 Cycles & $0.21(0.06)$ & $0.043(0.015)$ & $0.004(0.004)$ \\
1000 Cycles & $0.19(0.05)$ & $0.037(0.011)$ & $0.011(0.006)$ \\
\hline
\end{tabular}

*Values are shown as Mean (Std Dev), $n=5$. The vertical lines connect groups which are not statistically different $(p=0.05)$.

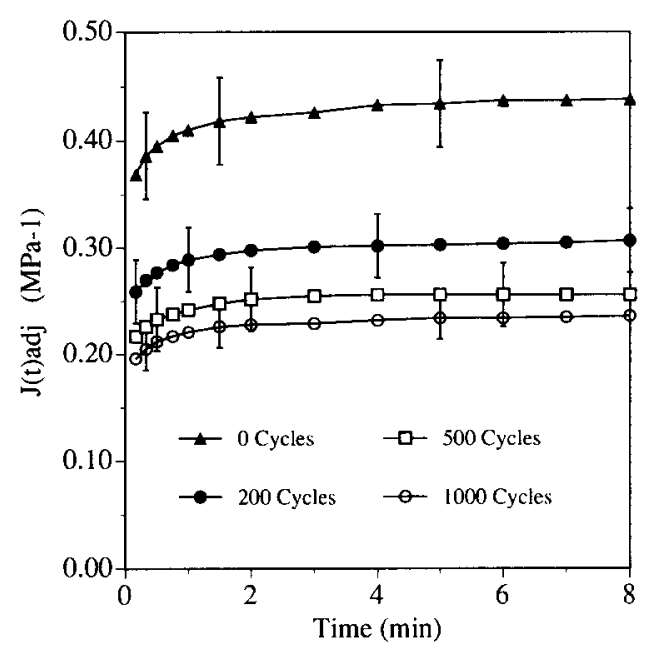

Fig. 3. Summary of the total compliance $(\mathrm{J}(\mathrm{t}) \mathrm{adj})$ of the elastics as a function of time. An increase in the number of stretching cycles caused a decrease in the total compliance of the elastics. Statistically, however, there were no differences among the groups stretched 200,500 , or 1000 times. Error bars represent one standard error of the mean.

cous behavior. With these elastics, the viscous component of the compliance was small and could have been eliminated from the analysis without compromising accuracy (Table 2). If polyurethane materials were tested, the viscous component would likely comprise more of the total compliance (Bishara and Andreasen, 1970).

The results from the evaluation of orthodontic elastics using compliance measurements agreed with those using force decay measurements. Both methods showed that repeated stretching had a negative effect on the performance of the elastics. The apparent slight recovery of the force between 1 and $3 \mathrm{~h}$ was not evident in the compliance data because these latter tests were completed $8 \mathrm{~min}$ after the repeated stretching. If additional compliance tests were performed 1 to $3 \mathrm{~h}$ after the repeated stretching, the compliance might be able to detect and verify the recovery phenomenon. Overall, the compliance method gave more detailed information about the viscoelastic properties of the elastics than the force decay method. In addition, the compliance is a more desirable method for comparison of elastics of different dimensions, since the dimensions of the elastic are accounted for in compliance calculations.

Both the force decay and compliance measurements showed that latex orthodontic elastics were remarkably stable despite significant repeated stretching. Further testing at elevated temperatures and in the presence of water or artificial saliva would give a more complete analysis of the clinical behavior of these materials. Extrapolation of these results to clinical situations should be reserved until these variables are incorporated into this testing model.

\section{ACKNOWLEDGMENTS}

This investigation was supported in part by Grant T32 DE07057 from the National Institute of Dental Research, Bethesda, MD 20892. The authors thank Kim Firestone for fabrication of the modifications in the stretching and compliance devices.

Received June 2,1992/Accepted December 30, 1992

Address correspondence and reprint requests to:

J. C. Wataha

University of Michigan School of Dentistry

Department of Prosthodontics

1011 N. University Avenue

Ann Arbor, MI 48109-1078 USA

\section{REFERENCES}

Andreasen GF, Bishara S (1970). Comparison of alastik chains with elastics involved with intra-arch molar to molar forces. Angle Orthod 40:151-158.

Ash JL, Nikolai RJ (1978). Relaxation of orthodontic elastomeric chains and modules in vitro and in vivo. J Dent Res 57:685-690.

Bishara S, Andreasen GF (1970). A comparison of time related forces between plastic alastiks and latex elastics. Angle Orthod 40:319-328.

Brantley SA, Salander S, Myers CL, Winders RV (1979). Effects of prestretching on force degradation characteristics of plastic modules. Angle Orthod 49:37-43.

Caddell RM (1980). Deformation and Fracture of Solids. Englewood Cliffs, N.J.: Prentice-Hall.

Chang HF (1987). Effects of instantaneous prestretching on force degradation characteristics of orthodontic plastic modules. Proc Natl Sci Counc Repub China 11:45-53.

Craig RG (1989). Restorative Dental Materials. 8th ed. St. Louis: C.V. Mosby.

Gere JM and Timoshenko SP (1984). Mechanics of Materials. 2nd ed. Boston: PWS Engineering.

Goldberg AJ (1974). Viscoelastic properties of silicone, polysulfide, and polyether impression materials. J Dent Res 53:1033-1039.

Kovatch JS, Lautenschlager EP, Apfel DA, Keller JC (1976). Load-extension-time behavior of orthodontic alastiks. J Dent Res 55:783-786.

Varner RE, Buck DL (1978). Force production and decay rate of alastik modules. J Biomed Mater Res 12:361-366.

Wheeler RC (1974). Dental Anatomy, Physiology and Occlusion. 5th ed. Philadelphia: W.B. Saunders.

Zarb GA, Bolender CL, Hickey JC, Carlsson GE (1990). Boucher's Prosthodontic Treatment for Edentulous Patients. 10th ed. St. Louis: C.V. Mosby. 